\title{
Phylogenetic Diversity and Spatial Distribution of the Microbial Community Associated with the Caribbean Deep-water Sponge Polymastia cf. corticata by 16S rRNA, $\operatorname{apr} A$, and $a m o A$ Gene Analysis
}

\author{
Birte Meyer • Jan Kuever
}

Received: 9 July 2007 / Accepted: 12 November 2007 / Published online: 10 January 2008

(C) Springer Science + Business Media, LLC 2007

\begin{abstract}
Denaturing gradient gel electrophoresis (DGGE)based analyses of $16 \mathrm{~S}$ rRNA, aprA, and amoA genes demonstrated that a phylogenetically diverse and complex microbial community was associated with the Caribbean deep-water sponge Polymastia cf. corticata Ridley and Dendy, 1887. From the 38 archaeal and bacterial 16S rRNA phylotypes identified, $53 \%$ branched into the spongespecific, monophyletic sequence clusters determined by previous studies (considering predominantly shallow-water sponge species), whereas $26 \%$ appeared to be $P$. cf. corticata specifically associated microorganisms ("specialists"); $21 \%$ of the phylotypes were confirmed to represent seawater- and sediment-derived proteobacterial species ("contaminants") acquired by filtration processes from the host environment. Consistently, the aprA and amoA genebased analyses indicated the presence of environmentally derived sulfur- and ammonia-oxidizers besides putative sponge-specific sulfur-oxidizing Gammaproteobacteria and Alphaproteobacteria and a sulfate-reducing archaeon. A sponge-specific, endosymbiotic sulfur cycle as described for marine oligochaetes is proposed to be also present in $P$. cf. corticata. Overall, the results of this work support the
\end{abstract}

Electronic supplementary material The online version of this article (doi:10.1007/s00248-007-9348-5) contains supplementary material, which is available to authorized users.

B. Meyer · J. Kuever

Max-Planck-Institute for Marine Microbiology,

Celsiusstrasse 1,

28359 Bremen, Germany

Present address:

J. Kuever $(\square)$

Bremen Institute for Materials Testing,

Paul-Feller-Strasse 1,

28199 Bremen, Germany

e-mail: kuever@mpa-bremen.de recent studies that demonstrated the sponge species specificity of the associated microbial community while the biogeography of the host collection site has only a minor influence on the composition. In $P$. cf. corticata, the specificity of the sponge-microbe associations is even extended to the spatial distribution of the microorganisms within the sponge body; distinct bacterial populations were associated with the different tissue sections, papillae, outer and inner cortex, and choanosome. The local distribution of a phylotype within $P$. cf. corticata correlated with its (1) phylogenetic affiliation, (2) classification as spongespecific or nonspecifically associated microorganism, and (3) potential ecological role in the host sponge.

\section{Introduction}

Sponges constitute the phylum Porifera, which is taxonomically divided into the three classes: Calcarea, Hexactinellida, and Demospongiae with the latter encompassing approximately $85 \%$ of the recognized species [23]. They are benthic, sessile filter feeders that depend on (dissolved) organic particle uptake from a continuous stream of water passing through their aquiferous canal system of channels and chambers. Particles including bacteria and single-celled eukaryotes can be captured by epithelial pinacocytes (forming the ectosome) at the sponge surface but are predominantly trapped from the filtered water within the choanocyte chambers-containing region of the sponge, the choanosome (or endosome). The food particles are transferred via transcytosis to the sponge cells of the interior mesohyl matrix. In some sponge species, a specialized area of the mesohyl that lacks choanocyte chambers but contains mineral deposits or collagen fibrils is located immediately below the exopinacoderm, the cortex. As part of the ectosome, the cortex has 
been presumed to act as a special supportive device for the openings of the canal system and as a protective layer of the endosome against superficial injury or strong currents $[1,56]$. The genus Polymastia Bowerbank, 1864 (Demospongiae, Tetractinomorpha, Hadromerida, Polymastiidae) with approximately 50 described species is characterized by their encrusting, spherical- or cushion-shaped sponges always with pore-bearing, inhalant and exhalant papillae and a cortex of the ectosomal skeleton that is composed of at least two layers $[4,43]$. The species Polymastia cf. corticata Ridley and Dendy, 1887 , is distinctive by its dense and leathery cortex (2 mm thickness; two distinct layers; intermediary layer collagenous), 100 inhalant and 4 to 5 exhalant papillae of approximately $8 \mathrm{~mm}$ height, and choanosomal bundles of spicules that stop below the cortex (the latter can be easily detached from the endosome). The species has been collected off the coast of Brazil and east of the Azores in a bathymetric range from 200 to $1,385 \mathrm{~m}[4,43]$.

Early microscopic and culture-based examinations demonstrated that large numbers of microbes populate the mesohyl matrix of many demosponges (termed "bacteriosponges") forming up to $40 \%$ of the sponge volume with densities of $10^{8}$ to $10^{10}$ bacteria per gram of sponge wet weight $[64,72]$. The hypothesis of a widespread, spongespecific microbial community that is distinctly different from the marine bacterioplankton that was postulated by Hentschel et al. $[15,16]$ and has been supported by others (for recent reviews, see [17, 19, 59, 67]). In contrast, the results of several recent diversity surveys contradict the existence of a general uniform sponge-associated microbial community regardless of sponge species and location. Instead, they provided evidence that the composition of the sponge-inhabiting microbial consortium depends on the host species [18, 22, 33, 60-63, 68]. A correlation between the presence of certain major bacterial taxonomic groups in the sponge microbiota and the geographical location of the host sponge was proposed by Hill et al. [18]. However, the presence of distinct microbial consortia in different sponge species sharing the same habitat indicated a low impact of the surrounding marine plankton for the sponge-bacteria associations [60, 62, 63, 68]. As recently demonstrated by Thiel et al. [63], the specificity of sponge-microbe associations extends to the spatial distribution of microbial populations within the sponge body: Distinct bacterial communities were found to inhabit the endosome and cortex of marine sponge Tethya aurantium; specifically associated phylotypes (e.g., cortex-associated members of the Bacteroidetes and Alphaproteobacteria) were identified for both regions.

The current knowledge about sponge-microbe associations is restricted to investigations of shallow-water species with the only exception of the bacterial 16S rRNA genebased analysis published by Olson and McCarthy [48]. The aim of the present study was to examine the phylogenetic composition and spatial distribution of the archaeal and bacterial community associated with a deep-water sponge $P$. cf. corticata by DGGE-based 16S rRNA and functional gene analyses. The analyses of functional genes that encode key enzymes of the dissimilatory sulfate reduction, sulfur oxidation, and ammonia oxidation pathway, e.g., aprA and amoA (coding for the alpha subunits of the dissimilatory APS reductase, AprA, and ammonia monooxygenase, AmoA), allow diversity surveys of certain physiological groups, e.g., sulfate-reducing, sulfur-oxidizing, and ammonia-oxidizing prokaryotes. The polyphyly of these physiological groups (see $[5,11,13,24,28,29,50,73]$ and references therein) restricts the concomitant detection of all recognized members by the use of single $16 \mathrm{~S}$ rRNA genetargeting probes or primer pairs and limits the identification of novel lineages in environmental analyses. In addition, the analysis of $16 \mathrm{~S}$ rRNA genes cannot provide an unambiguous link between the genetic identity of an uncultured microorganism and its physiological or metabolic capacity. Analyses of functional genes like aprA and amoA circumvent these limitations and (although complicated by lateral gene transfer events of aprA [39, 40]) have been successfully applied for biodiversity studies $[2,14,31$, $41,46,47]$. They were used to determine the phylogenetic complexity of the $P$. cf. corticata-associated microbial communities putatively involved in sulfur and nitrogen cycling within the sponge.

\section{Materials and Methods}

\section{Sampling}

The deep-water sponge was collected by a chain bag dredge from a depth of $1,127 \mathrm{~m}$ at the Kahouanne Basin (Lesser Antilles, Caribbean Sea) $\left(16^{\circ} 28.80^{\prime} \mathrm{N}, 61^{\circ} 58.66^{\prime} \mathrm{W}\right)$ in January 2001 (RV Sonne cruise SO-154). Ambient seawater (temperature $5^{\circ} \mathrm{C}$ ) was sampled from the surface of undisturbed sediment cores with a sterile syringe; all samples were immediately frozen and stored at $-20^{\circ} \mathrm{C}$ until further molecular investigation. In the laboratory, the sponge was washed carefully three times in autoclaved artificial seawater before cutting. Small subsamples (2$3 \mathrm{~cm}^{3}$ tissue cubes) were fixed in $4 \%$ formaldehyde, placed in $70 \%$ ethanol, and sent to the Senckenberg Museum, Frankfurt am Main, Germany, for sponge identification. Examination of its general morphological features including spicules geometry of the tissue sample (deposited under the registration number SMF 9633) classified this deepwater specimen as $P$. cf. corticata Ridley and Dendy, 1887, a member of the Polymastiidae (Demospongiae, Hadromerida) (D. Janussen, pers. comm.). For molecular analy- 
sis, two sponge tissue subsamples were separated into papillae, outer cortex (including ectopinacoderm), inner cortex, and endosome (choanosome) sections (Fig. 1) with a sterile scalpel. The tissue sections were gently rinsed in autoclaved artificial seawater to remove loosely attached bacteria from the surfaces and cut into small pieces before DNA extraction. Two seawater samples (each $200 \mathrm{ml}$ ) were filtered through a Sterivex filter $(0.2 \mu \mathrm{M}$ pore size, Millipore).

\section{Genomic DNA Extraction}

Total genomic DNA were extracted from the four different sponge tissue sections in duplicate and purified using the DNeasy ${ }^{\circledR}$ Tissue Kit (Qiagen, Hilden, Germany) following the manufacturer's protocol for Gram-positive bacteria and animal tissue. Genomic DNA from both filtered seawater samples was extracted after five cycles of thawing at $30^{\circ} \mathrm{C}$ and freezing in liquid nitrogen using the protocol of Zhou et al. [74]. The DNA concentrations were estimated spectrophotometrically, whereas its integrity was examined visually by gel electrophoresis on $0.8 \%(w / v)$ agarose gels run in 1x Tris-borate-EDTA (TBE) buffer followed by ethidium bromide staining $\left(0.5 \mathrm{mg} \mathrm{l}^{-1}\right)$. The extracted DNA (dissolved in $10 \mathrm{mM}$ Tris-HCl, $1 \mathrm{mM}$ EDTA, $\mathrm{pH}$ 7.5) was stored at $-20^{\circ} \mathrm{C}$ until further analysis.

\section{PCR Amplification of Partial 28S rRNA Gene}

Besides its morphological identification, 28S rRNA gene fragments $\left(\mathrm{C} 1, \mathrm{D} 1, \mathrm{C} 2\right.$, and $\mathrm{D} 2$ domains at the $5^{\prime}$-end) were amplified from the sponge-derived genomic DNA using the primers and polymerase chain reaction (PCR) protocol of Chombard et al. [6] to confirm the former morphological classification by molecular systematics (for PCR primer

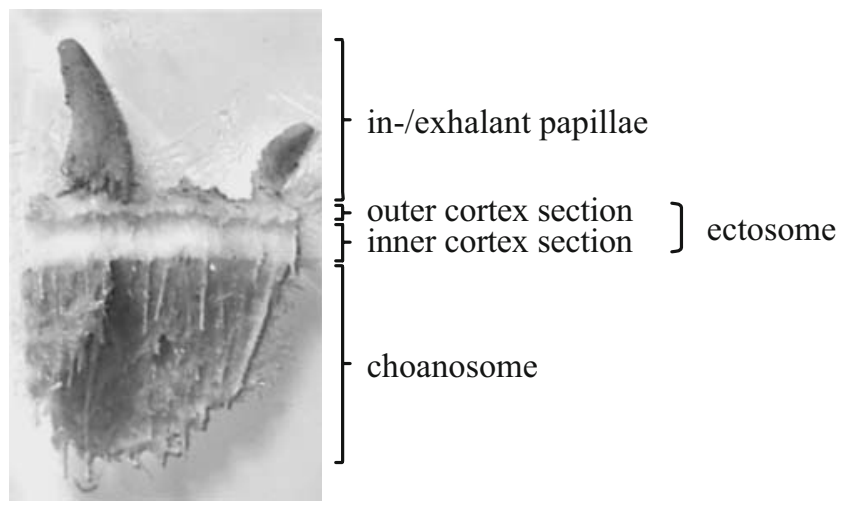

Figure 1 Photograph of a cross-section of Polymastia cf. corticata showing the examined morphologically different tissue regions, (1) papillae, (2) outer section of the cortex including the exopinacoderm and (3) inner (collagenous) section of the cortex (comprising the ectosome), and (4) the choanosome (endosome) sequences and detailed thermocycling conditions see Table S1 of the Electronic Supplementary Material).

PCR Amplification of Partial 16S rRNA, aprA, and amoA genes for Subsequent Double Gradient Denaturing Gradient Gel Electrophoresis Analysis

In general, PCR mixtures (50 $\mu$ l total volume) contained $1 \mathrm{x}$ REDTaq PCR reaction buffer (Sigma-Aldrich, St. Louis, Missouri, USA), $0.3 \mathrm{mg} \mathrm{ml}^{-1}$ bovine serum albumin (BSA), $200 \mu \mathrm{M}$ deoxynucleoside triphosphates (dNTPs)

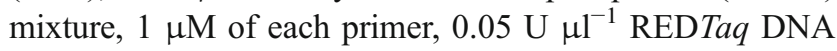
Polymerase, and $100 \mathrm{ng}$ genomic DNA as template (negative controls with water). Partial 16S rRNA gene amplification for subsequent double gradient denaturing gradient gel electrophoresis (DG-DGGE) analysis was performed using the primer sets (1) GM5F-GC clamp (341F) and 907R for Bacteria [45], (2) Arch516F-GC clamp (K. Knittel, unpublished) and Arch958R [7] for Archaea, and (3) CTO189f-GC clamp and CTO654r specific for betaproteobacterial ammonia-oxidizers [30]. An approximately $0.4-\mathrm{kb}$ aprA gene fragment was amplified using the primer set AprA-1-FW and AprA-5-RV with GC clamp [41]. An approximately $0.5-\mathrm{kb}$ amoA gene fragment was yielded applying the primer pair AmoA-1F and AmoA-2R-TC [46] (for details see Table S1 of the Electronic Supplementary Material). Duplicate amplifications were performed from each sponge tissue section and seawater DNA sample. The PCR products were visually analyzed by electrophoresis of aliquots ( $10 \%$ of the reaction volume) on $2 \%$ agarose gels $(w / v)$ run in $1 \mathrm{x}$ TBE buffer stained with ethidium bromide $\left(0.5 \mathrm{mg}^{-1}\right)$ to verify correct amplicon size. If necessary, amplicons of the expected gene fragment size were purified before further analysis using either the QIAquick gel extraction kit (Qiagen, Hilden, Germany) or the Perfectprep gel cleanup sample kit (Eppendorf, Hamburg, Germany) following the supplier's recommendations.

\section{DG-DGGE Analysis}

The DG-DGGE analyses of the aforementioned duplicate 16S rRNA, aprA, and amoA amplicons from each sponge tissue type and seawater DNA sample were performed using the D-GENETM and D-CODE ${ }^{\mathrm{TM}}$ system (Bio-Rad, Munich, Germany). DG-DGGE gels (1.0 mm thick) were poured with an polyacrylamide gradient from $6 \%$ to $8 \%$ of acrylamide/bis-acrylamide stock solution, 37.5:1 (v/v) (Bio$\mathrm{Rad}$ ) superimposed over a colinear denaturant gradient $[100 \%$ denaturant corresponds to $7 \mathrm{M}$ urea and $40 \%(v / v)$ formamide, deionized with AG501-X8 mixed bed resin (Bio-Rad)], which varied for the different genes analyzed in this study (see Table S2 of the Electronic Supplementary Material). Gradients were formed using a Bio-Rad Gradient 
Former Model 385. Twenty microliters of the PCR samples were mixed with $6 \mu \mathrm{l}$ of dye solution $[0.1 \%$ bromphenol blue $(w / v), 70 \%$ glycerol $(v / v)]$ and applied to the gels. Triplicate gel runs were carried out as reported elsewhere (for references see Table S2 of the Electronic Supplementary Material) followed by ethidium bromide staining $\left(0.5 \mathrm{mg} \mathrm{l}^{-1}\right)$ for $15 \mathrm{~min}$ and subsequent destaining in double-distilled water for $10 \mathrm{~min}$. The DNA bands were visualized on a UV transillumination table (Biometra, Göttingen, Germany); persisting and dominant bands were excised from multiple lanes of the polyacrylamide gels with ethyl alcohol-sterilized scalpel, incubated in $50 \mu \mathrm{l}$ Tris$\mathrm{HCl}, \mathrm{pH} 8.0$, overnight at $4^{\circ} \mathrm{C}$, and reamplified using $1 \mu \mathrm{l}$ of the eluate as template and PCR conditions as described above. The purity and migration behavior of the reamplification products of the bands were checked by DGDGGE. The reamplification products were purified from free PCR primers using either the QIAquick gel extraction kit (Qiagen) or the Perfectprep gel cleanup sample kit (Eppendorf) following the supplier's recommendations.

\section{Nucleotide Sequencing}

All reamplification products of the DG-DGGE bands were sequenced directly in both directions using the respective amplification primers and the ABI Prism BigDye terminator cycle sequencing ready reaction kit (Applied Biosystems, Foster City, USA) according to the manufacturer's instructions. Sequencing reactions were run on an ABI PRISM ${ }^{\circledR} 3100$ Genetic Analyzer (Applied Biosystems).

\section{Phylogenetic Analysis}

The partial 16S rRNA sequences obtained from DGGE analysis were checked for chimeras with the program CHECK_CHIMERA of the Ribosomal Database Project, added to the 16S rRNA sequence database of the Technical University Munich (Germany) using the automatic alignment function ARB_Align implemented in the ARB software program package (http://www.arb-home.de), and manually corrected. The sequences were maintained separately according to their source (sponge tissue type, seawater); each set of sequences was grouped into phylotypes, i.e., operational taxonomic units (OTUs), based on a $>99 \%$ identity cutoff. Only one sequence per OTU and tissue type/seawater was used for further analysis. The closest phylogenetic relatives of each phylotype were identified by comparison to the National Center for Biotechnology Information (NCBI) GenBank database using the Basic Local Alignment Search Tool (BLAST) analysis tools (www.ncbi.nlm.nih.gov/BLAST/). For phylogenetic analysis, the online version of PhyML (http://atgc. lirmm.fr/phyml) was used. Maximum-likelihood trees were calculated based on the near full-length 16S rRNA reference sequences received from the database; their robustness was tested by bootstrap analysis with 100 resamplings. Subsequently, these trees were imported into ARB and the DGGE analysis-derived short sequences were individually added by using the QUICK ADD parsimony tool of ARB without allowing changes in the overall tree topology. The phylogenetic positions of the short sequences were additionally verified by bootstrap analysis with 100 resamplings (maximum-likelihood method). To determine the specificity of the microbial associations, the detected phylotypes from $P$. cf. corticata were classified as (1) "specialists", (2) "sponge associates", or (3) "generalists" depending on their presence in (1) this host species only, (2) several sponge species but absent from seawater, or (3) several sponge species and seawater in accordance to Taylor et al. [60]; the enumeration of the sponge-associated bacterial (SAB) and archaeal (SAA) phylogenetic clusters is based on the previous studies of Hentschel et al. [16], Thiel et al. [63], Holmes and Blanch [22], and Lee et al. [32].

The aprA and amoA nucleotide sequence data obtained from DGGE analysis were assembled and manually corrected using the Bioedit (version 7.0.5) sequence alignment editor (http://www.mbio.ncsu.edu/BioEdit/bioedit.html). The sequences were maintained separately according to their source (sponge tissue type, seawater); each set of sequences was grouped into phylotypes based on a $>99 \%$ identity cutoff. Only one sequence per OTU and tissue type/seawater was used for further analysis. BLAST searches in the public databases for homologous sequences of the partial AmoA sequences were performed. The partial and complete AmoA sequences were automatically aligned using the Web server Tcoffee@igs (http://igs-server.cnrsmrs.fr/Tcoffee/); the initial alignment was refined manually. The partial AprA sequences were integrated into the persisting Apr alignment of sulfate-reducing and sulfuroxidizing reference strains $[39,40]$ including all full-length Apr sequences available from the public databases. The AmoA and AprA data sets were phylogenetically analyzed using PhyML. Regions of insertions and deletions (indels) were omitted. The maximum-likelihood method-based phylogenetic trees were constructed using the global rearrangement and randomized species input order options and the JTT matrix as amino acid replacement model. Statistical support is given by bootstrap analysis with 100 resamplings.

\section{GenBank Accession Numbers}

The nucleotide sequence data reported in this article are available under the GenBank accession numbers EU005552 (28S rRNA gene), EU005553-EU005595 and EU005641EU005648 (16S rRNA gene), EU005596-EU005620 (aprA gene), and EU005621-EU005640 (amoA gene). 
Figure 2 DGGE banding patterns of amplified 16S rRNA, $a p r A$, and $a m o A$ gene fragments using DNA samples from sponge tissue sections, papillae $(\mathrm{Pa})$, outer cortex $(O C)$, inner cortex $(I C)$, and choanosome (Ch) of Caribbean P. cf. corticata and sponge ambient seawater (SAS) collected at the Kahouanne Basin (see Fig. 1). 16S rRNA gene-specific diversity analysis was performed applying universal bacterial (a), universal archaeal (b), and betaproteobacterial ammoniaoxidizer-specific (b) genetargeting primer pairs in PCR. Diversity analysis of functional genes was performed using SRP- and SOB-specific aprA gene-targeting primers (d) and betaproteobacterial ammoniaoxidizer-specific amoA genetargeting primers (e). Numbered DGGE bands were excised from replicate gels and successfully sequenced (phylogenetic analyses of retrieved sequences, see Figs. 3, 4, and 5) a

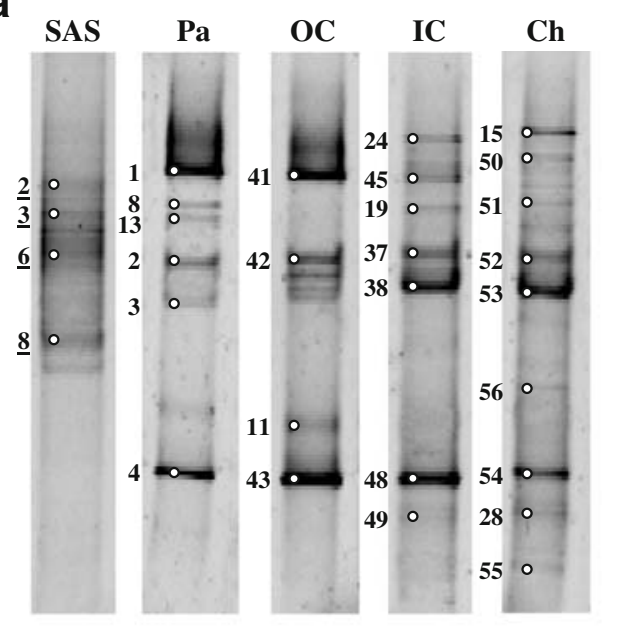

C
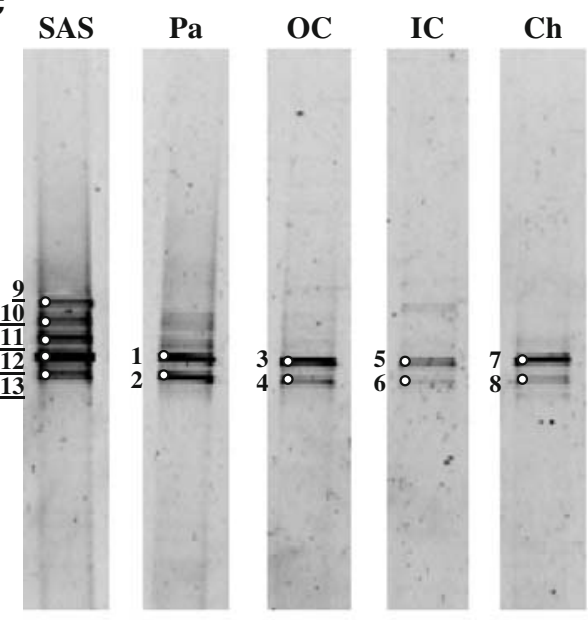

b

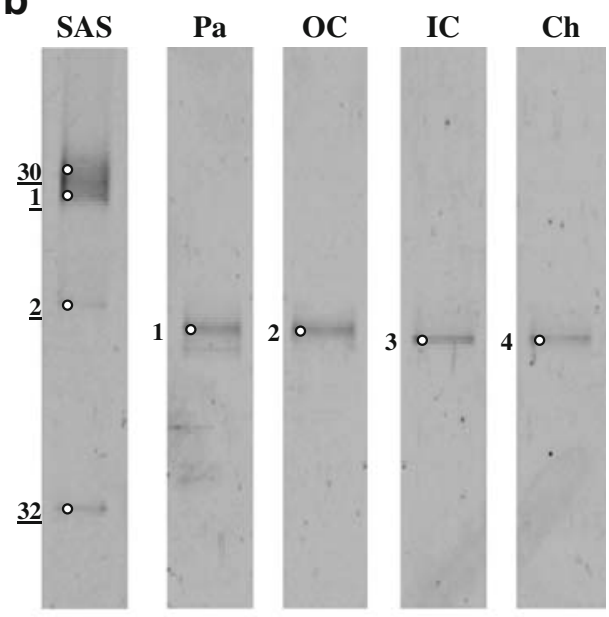

d d SAS
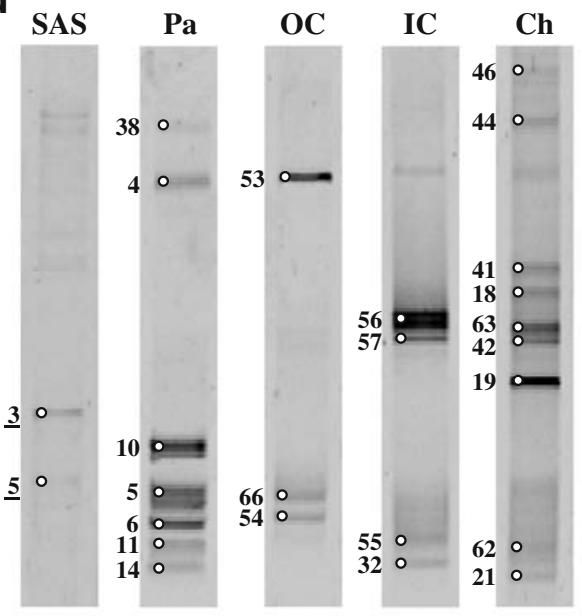

e

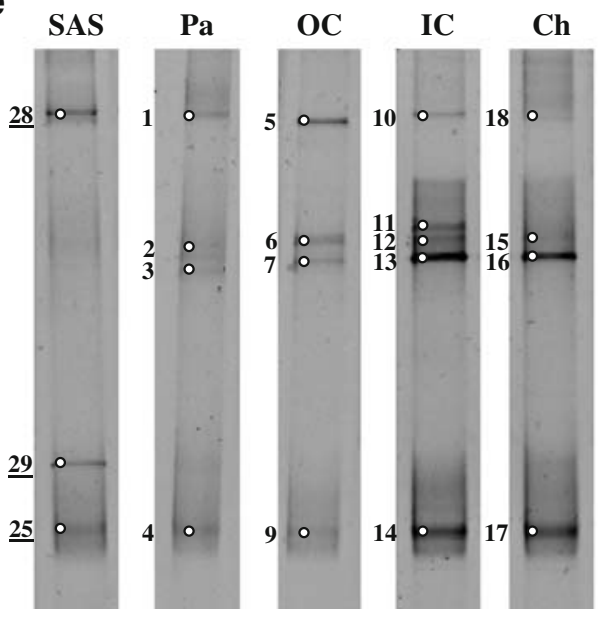

\section{Results}

\section{DGGE}

DGGE was used to fingerprint the microbial community in P. cf. corticata (Fig. 1). The banding patterns of the same tissue type were identical, indicating no genomic DNA extraction and PCR amplification bias. The banding patterns of DGGE analyses using universal archaeal, bacterial, and aprA gene-targeting primers showed the presence of different microbial communities in the inner and outer regions of $P$. cf. corticata (Fig. 2a, b, d). In addition, all tissue 




Figure 3 Phylogenetic trees based on the 16S rRNA sequences obtained from the $P$. cf. corticata-associated microbial community and host sponge surrounding seawater with the three 16S rRNA genetargeting primer sets used in this study and related sequences belonging to the Alphaproteobacteria, Betaproteobacteria, and Deltaproteobacteria (a); Gammaproteobacteria (b); Acidobacteria and Nitrospira (c); and Actinobacteria and Archaea (d). Sequences obtained from $P$. cf. corticata are shown in bold type and highlighted by dark-gray boxes, whereas those obtained from the host sponge ambient seawater are underlined. The monophyletic, sponge-associated bacterial and archaeal 16S rRNA clusters are highlighted by light-gray boxes. The $P$. cf. corticata-derived sequences are classified into clusters of $P$. cf. corticata specialists ("PmCo specialist"), general "sponge-associated" Bacteria and Archaea (SAB, SAA) and "generalists" ("generalist" groups formed by other sponge species-derived sequences are framed by dashed lines) according to Taylor et al. [60]. Maximum-likelihood bootstrap resampling values greater than $50 \%$ (100 resamplings) are indicated near the nodes. The 16S rRNA gene sequence of Cenarchaeum symbiosum was used as outgroup reference. The scale bar corresponds to $10 \%$ estimated sequence divergence sections of the sponge differed in their DGGE banding pattern from the sponge ambient seawater (SAS) samples. Archaeal and bacterial phylotypes specifically associated with the distinct sponge regions were represented by DGGE bands that were exclusively present in all papillae, outer cortex, inner cortex, or choanosome samples, respectively, but absent in seawater (Fig. 2a, b, d). Other bands were found in all sponge tissue samples. Contrarily, the DGGE banding patterns of the betaproteobacterial ammonia-oxidizer-specific 16S rRNA and amoA gene-based analyses were highly similar (1) between the distinct sponge tissue types and (2) between sponge and ambient seawater (Fig. 2c and e). Phylotypes specifically associated with $P$. cf. corticata that were represented by DGGE bands exclusively found in the sponge samples (but not in seawater) were only detected by the amo $A$ gene-based analysis (Fig. 2e). 


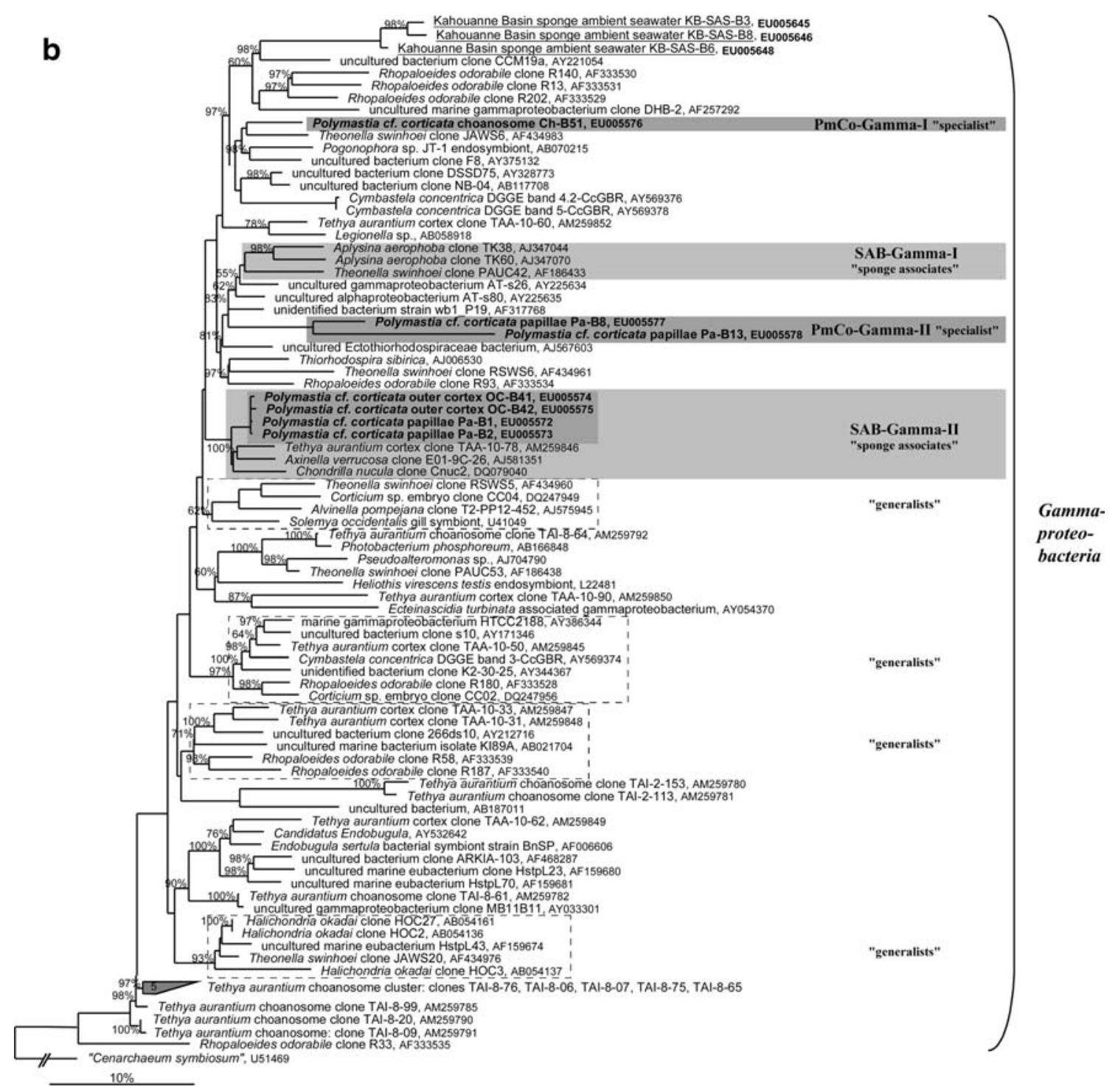

Figure 3 (continued)

Phylogenetic Analysis of Partial 16S rRNA Gene Sequences

A total of 38 OTUs was identified in $P$. cf. corticata forming 18 distinct sequence clusters. The sequences fell into eight different archaeal and bacterial divisions, the Crenarchaeota, Alphaproteobacteria, Betaproteobacteria, Gammaproteobacteria, Deltaproteobacteria, Acidobacteria, Actinobacteria, and Nitrospira (Fig. 3). In agreement with microbial communities associated with other examined deep-water sponges [48], no phylotype related to the cyanobacterial lineage was identified in the deep-water specimen of $P$. cf. corticata. Members of the latter phototrophic group are abundant in shallow-water sponges [16, $18,51,60,61,63]$. Twenty of the aforementioned 38 phylotypes $(53 \%)$ were most closely affiliated with other sponge-derived sequences previously found in Tethya aurantium, Rhopaloides odorabile, Theonella swinhoei, Latrunculia apicalis, Halichondria panicea, Aplysina aerophoba, Sclerotiderma sp., Chondrilla nucula, Petrosia sp., Suberites sp., and Axinella verucosa from different geographical locations (predominantly shallow-water habitats). These phylotypes comprised the eight sponge-specific, monophyletic clusters SAB-Beta-I [63], SAB-Gamma-II, SAB-Delta-I and SAB-Delta-II, SAB-Acido-III, SABActino-III, SAB-Nitrospira-I [16], and SAA-Cren-I (sponge group C) [22, 32] (classified as "sponge associates"). It is interesting to note that the detected alphaproteobacterial, most gammaproteobacterial, actinobacterial, and crenarchaeal phylotypes appeared to represent $P$. cf. corticata host- 


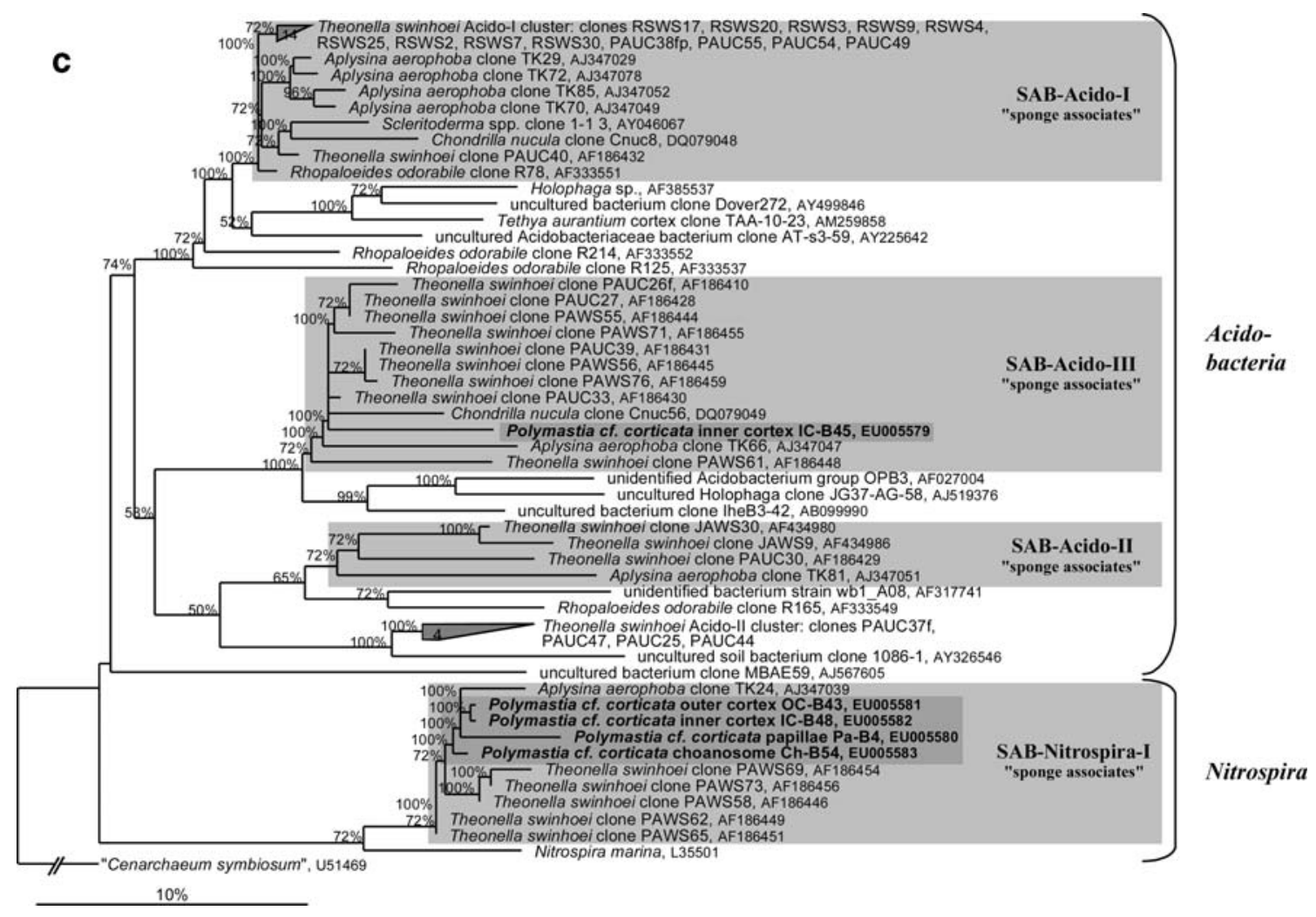

Figure 3 (continued)

specific microorganisms ("specialists" PmCo-Alpha-I, PmCo-Gamma-I/-II, PmCo-Actino-I/-II/-III, and PmCoCren-I) not present in the ambient seawater and other sponge species. Based on the current database, these 10 phylotypes $(26 \%)$ were only moderately related to other sponge-derived sequences but affiliated to environmental sequences received from other marine macroorganisms (Pogonophora endosymbionts; PmCo-Gamma-II), aquatic microbial formations in Nullarbor caves [21] (PmCoGamma-I, PmCo-Actino-I), inactive deep-sea hydrothermal vent chimneys [57] (PmCo-Actino-II), and deep-sea sediments [65] (PmCo-Cren-I). Indeed, by the use of betaproteobacterial ammonia-oxidizer-specific primers [30], close relatives of uncultured marine Nitrosospira [10] were detected in the sponge tissue and in the host surrounding seawater (classified as "generalists" PmCo-Beta-I and PmCo-Beta-II).

The bacterioplankton assemblage of the sponge ambient seawater at the Kahouanne Basin (1,127 m depth) was phylogenetically less diverse with respect to the complex microbial community associated with $P$. cf. corticata (Fig. 3). The detected phylotypes were most closely affiliated with seawater- and deep-sea sediment-derived sequences of uncultured members of the marine group-I Crenarchaeota (MG-I, group C1a- $\alpha$ ) [65], Euryarchaeota [38], Nitrosospira [10], uncultured Gammaproteobacteria and Bacteroidetes (respective SAS-B2 16S rRNA sequence is not shown in Fig. 3; closest relative is AJ567605; M.X. Xu, P. Wang, F.P. Wang, and X. Xiao, unpublished results).

Phylogenetic Analysis of Partial AprA and AmoA Sequences

The aprA gene-based analysis allowed the detection of six phylotypes that are indicative for the presence of five sulfuroxidizing alphaproteobacterial and gammaproteobacterial species and one sulfate-reducing archaeon in the tissue of P. cf. corticata (Fig. 4). The alphaproteobacterial SOBphylotypes were most closely related to AprA sequences of cultured members of the SAR11 clade [12] (PmCo-sulfuroxidizer-I to PmCo-sulfur-oxidizer-III) and the LGT-affected Thiobacillus plumbophilus (PmCo-sulfur-oxidizer-IV). Because representatives of the alphaproteobacterial clusters I to III have also been found to be abundant in deep-sea sediments of the Kahouanne Basin and the sponge ambient seawater (Fig. 4), the corresponding SOB species were classified as "generalists". The gammaproteobacterial SOBphylotype (PmCo-sulfur-oxidizer-V) was moderately affiliated to AprA sequences of uncultured Thiothrix species, which have been found in cold seep Beggiatoa-mats at the Hydrate Ridge, Oregon [41]. All identified SOB-phylotypes could not be assigned to any detected 16S rRNA gene- 


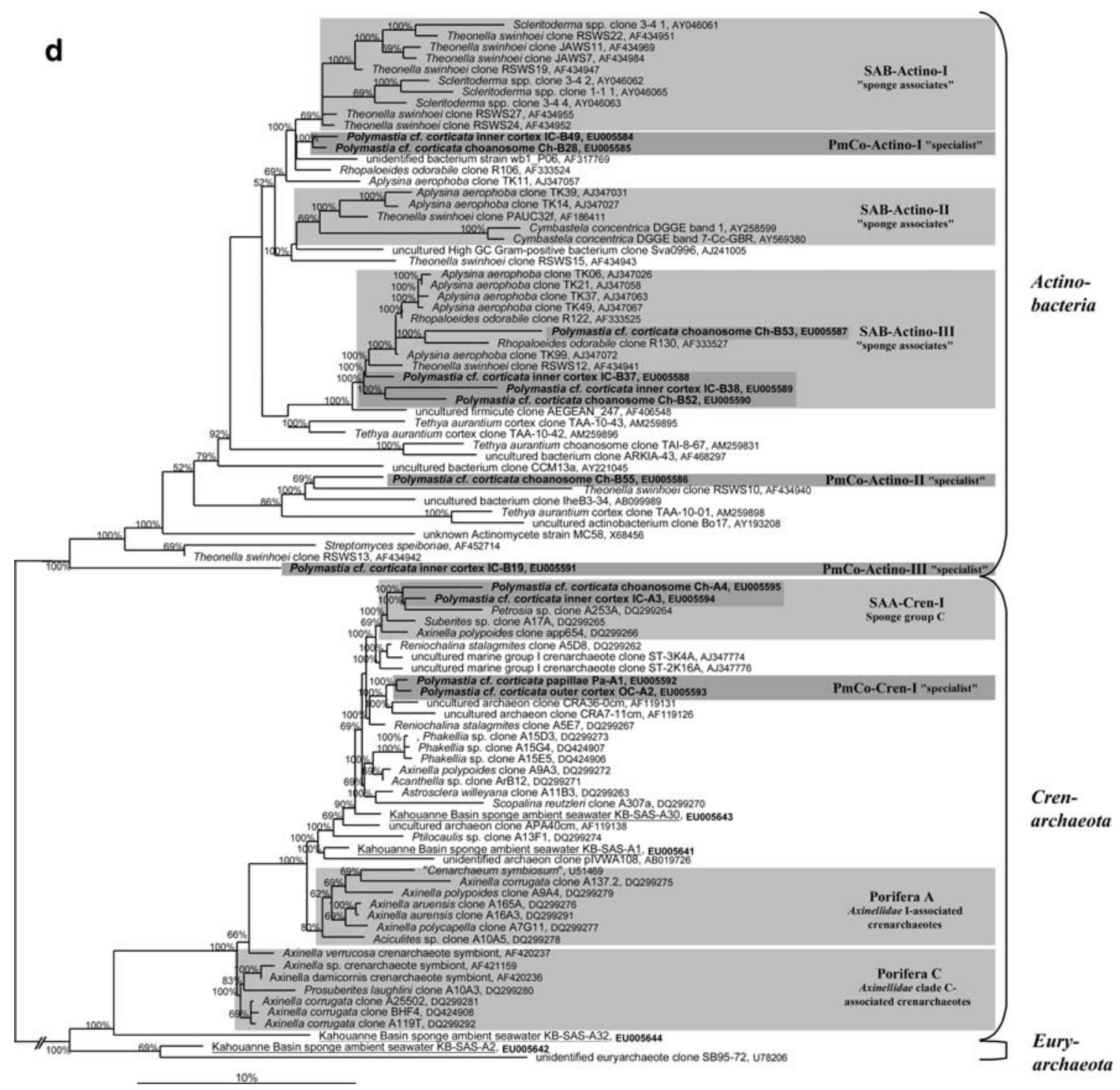

Figure 3 (continued)

based OTU. Besides, a SRP-phylotype was detected that is most closely related to the AprA sequences of Archaeoglobus members; a corresponding euryarchaeal species was not identified by the 16S rRNA gene-based analysis.

The amoA gene-based analysis (Betaproteobacteriaspecific primers) allowed the detection of nearly identical phylotypes (PmCo-ammonia-oxidizer-I and PmCoammonia-oxidizer-II) in the sponge tissue and the host surrounding seawater (Fig. 5); closely related environmental sequences have also been reported from diverse sediment or seawater-sediment interface samples of other habitats $[2,14$, 31]. The AmoA sequence clusters corresponded to the uncultured Nitrosospira sequence clusters that have been identified by the group-specific 16S rRNA gene analysis (Fig. 3).
Spatial Distribution of the Sponge-Associated Microbial Community

The phylogenetic investigations of different tissue regions from P. cf. corticata (Fig. 1) demonstrated high variability in the microbial communities associated with the sponge papillae/outer cortex and the inner cortex/choanosome (Figs. 3, 4, and 5, summarized in Table 1). The 16S rRNA gene-based analysis indicated that the highest phylogenetic diversity is present in the inner region of the sponge, the choanosome. From the total of 38 different 16S rRNA gene-based phylotypes, 12 and 10 OTUs were detected in the choanosome and the inner cortex, respectively, whereas only 7 and 9 OTUs were found in the outer cortex and in the papillae tissue sections, respectively. The members of 


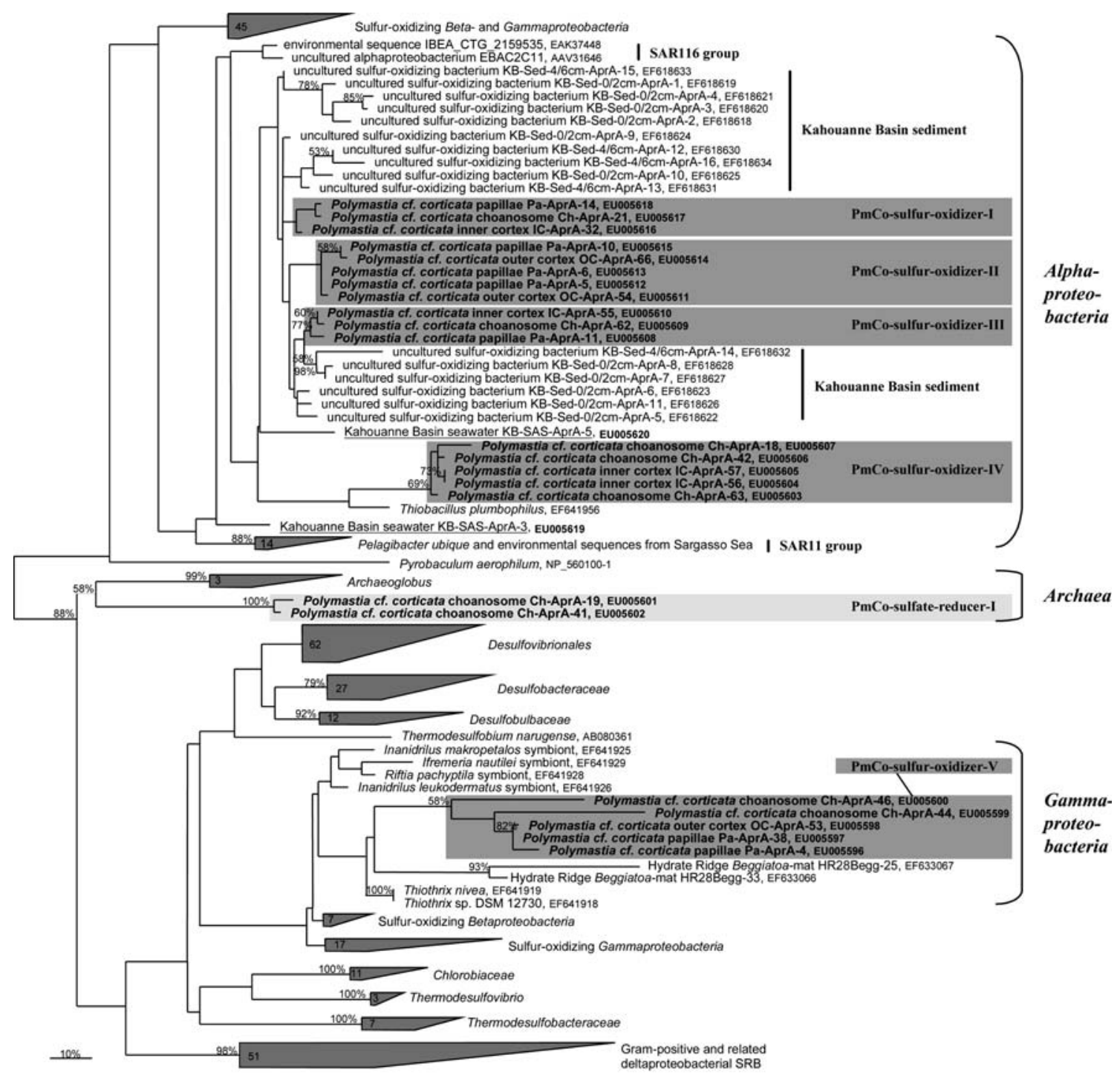

Figure 4 Phylogenetic tree based on the AprA sequences obtained from the $P$. cf. corticata-associated microbial community, the host sponge surrounding seawater, and adjacent sediment samples from the Kahouanne Basin. SRP- and SOB-type sequences received from $P$. cf. corticata are shown in bold type and highlighted by light-gray and dark-gray boxes, respectively; those obtained from the host sponge

the different archaeal and bacterial divisions were not evenly distributed within the sponge body but appeared to be associated with distinct parts of the host tissue. Five of the eight general sponge-specific clusters (SAB-Delta-I and SAB-Delta-II, SAB-Acido-III, SAB-Actino-III, SAA-CrenI, 11 phylotypes) and all $P$. cf. corticata-specifically associated actinobacterial phylotypes (PmCo-Actino-I, PmCo-Actino-II, and PmCo-Actino-III, 4 phylotypes) were exclusively present in the inner cortex and the choanosome. Thus, the members of the Deltaproteobacteria, Acidobacteria, and Actinobacteria were restricted to the inner parts of this sponge. In contrast, four of the five $P$. cf. corticata-derived sequence clusters that were exclusively identified in the ambient seawater are underlined. The taxonomic classification of the SRP and SOB reference strains and affiliated sponge-derived sequences is indicated. Maximum-likelihood bootstrap resampling values greater than $50 \%$ (100 resamplings) are indicated near the nodes. The scale bar corresponds to $10 \%$ estimated sequence divergence

sponge surface regions belonged to the Alphaproteobacteria, Betaproteobacteria, and Gammaproteobacteria (8 phylotypes). The OTUs comprised only two general spongespecific clusters (SAB-Beta-I, SAB-Gamma-II) besides four putative "specialists" clusters (PmCo-Alpha-I, PmCo-GammaII, PmCo-Cren-I) whose phylotypes were affiliated with nonsponge-derived sequences received from diverse habitats. The Crenarchaeota associated with the papillae and outer cortex sections were distinct to those found in the inner cortex and choanosome. Notably, with the exception of PmCoGamma-I, no phylotype obtained from the choanosome or the inner cortex section was closely related to environmental sequences found in seawater and sediment samples. 


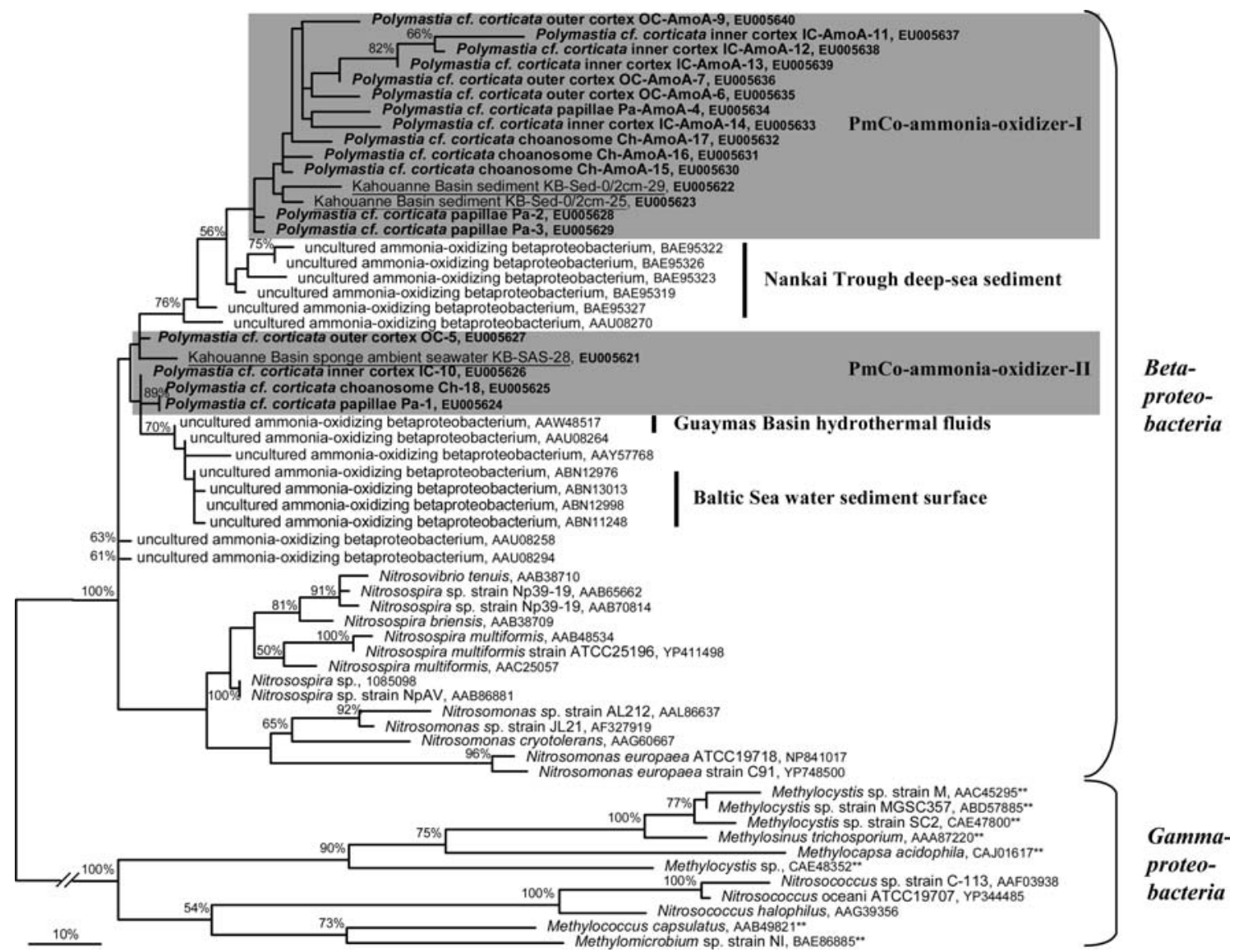

Figure 5 Phylogenetic tree based on the AmoA sequences obtained from the $P$. cf. corticata-associated microbial community and host sponge surrounding seawater including related (reference strain and environmental) sequences belonging to the Betaproteobacteria and Gammaproteobacteria. Sequences received from P. cf. corticata are shown in bold type and highlighted by dark-gray boxes, whereas those obtained from the host sponge ambient seawater are underlined. The taxonomic classification of the ammonia-oxidizing proteobacterial reference strains and affiliated sponge-derived sequences is indicated. Maximum-likelihood bootstrap resampling values greater than $50 \%$ (100 resamplings) are indicated near the nodes. The AmoA sequences of the Gammaproteobacteria were used as outgroup reference. The scale bar corresponds to $10 \%$ estimated sequence divergence

Table 1 Spatial distribution of phylotypes from the major microbial taxonomic/physiological groups identified in different tissue sections of $P$. cf. corticata by DGGE analysis of PCR-amplified $16 \mathrm{~S}$ rRNA, aprA, and amoA gene fragments

\begin{tabular}{|c|c|c|c|c|}
\hline Taxonomic/physiological group & Papillae & Outer cortex & Inner cortex & Choanosome \\
\hline \multicolumn{5}{|l|}{ 16S rRNA gene-based analysis } \\
\hline Crenarchaeota & + & + & + & + \\
\hline Alphaproteobacteria & + & + & - & - \\
\hline Betaproteobacteria $^{\mathrm{a}}$ & + & ++ & ++ & ++ \\
\hline Gammaproteobacteria & ++ & ++ & - & + \\
\hline Deltaproteobacteria & - & - & ++ & ++ \\
\hline Actinobacteria & - & - & ++ & ++ \\
\hline Acidobacteria & - & - & + & + \\
\hline Nitrospira & + & + & + & + \\
\hline \multicolumn{5}{|l|}{ aprA gene-based analysis } \\
\hline Sulfate-reducing prokaryotes & - & - & - & + \\
\hline Sulfur-oxidizing bacteria & ++ & ++ & ++ & ++ \\
\hline \multicolumn{5}{|l|}{ amoA gene-based analysis } \\
\hline Ammonia-oxidizing Betaproteobacteria & + & + & + & + \\
\hline
\end{tabular}

-: no phylotype affiliated with this major taxonomic/physiological group identified, +: phylotype affiliated with this major taxonomic/ physiological group identified, ++: two or more distinct phylotypes affiliated with this major taxonomic/physiological group identified

${ }^{a}$ Phylotypes retrieved from universal bacterial and betaproteobacterial-specific 16S rRNA gene analysis 
Consistent with the 16S rRNA analysis, the aprA genebased analysis revealed that the highest phylogenetic complexity was present in the choanosome of $P$. cf. corticata. In accordance to the 16S rRNA gene-observed local variability of the microbial community structure, the members of the six identified sulfur-oxidizing and sulfatereducing lineages differed significantly in their distribution within the host sponge. Whereas the gammaproteobacterial SOB (Thiothrix spp.-affiliated cluster V) and most alphaproteobacterial SOB species (potential "generalist" clusters PmCo-sulfur-oxidizer-I to PmCo-sulfur-oxidizer-III) were present in the entire sponge body, the putative spongespecific alphaproteobacterial sulfur-oxidizers (Thiobacillus plumbophilus-affiliated cluster IV) and the archaeal sulfatereducing strains (PmCo-sulfate-reducer-I) were restricted to the inner tissue sections. In support of the 16S rRNA analysis results obtained with the group-specific primers, the amo $A$ gene-based analysis showed the ubiquitous presence of two potential ammonia-oxidizing betaproteobacterial species in the sponge body.

\section{Discussion}

Microbial Diversity in the Caribbean Deep-water Sponge Polymastia cf. corticata in Comparison to Other Sponge Species

The 16S rRNA gene-based diversity analysis of the deepwater sponge $P$. cf. corticata collected at the Kahouanne Basin in the Caribbean Sea revealed its associated microbial community to be as phylogenetically complex and diverse as reported for the shallow-water sponge species [16, 18, 33, 60-63, 68]. Of the $P$. cf. corticata-associated phylotypes, $53 \%$ belonged to $16 \mathrm{~S}$ rRNA sequence clusters that were strictly confined to sponges ("sponge associates" groups SAB-Beta-I, SAB-Gamma-II, SAB-Delta-I and SAB-Delta-II, SAB-Acido-III, SAB-Actino-III, SAB-Nitrospira-I, and SAA-Cren-I; see Fig. 3). The residual $47 \%$ of the detected OTUs, however, did not branch into any of the recognized sponge-specific, monophyletic clusters $[15,16$, 19, 22, 59, 67]. Whereas the PmCo-Beta-I and PmCo-BetaII members have been confirmed to be sponge-unspecific, the PmCo-Gamma-I, PmCo-Gamma-II, PmCo-Alpha-I, PmCo-Actino-I, PmCo-Actino-II, PmCo-Actino-III, and PmCo-Cren-I phylotypes might represent $P$. cf. corticataspecifically associated microorganisms ("specialists"). By the increasing number of environmental sequences available in the databases, identical free-living relatives of these currently designated "specialists" might be identified in the future and change their classification status into "generalists." Indeed, most sponge-derived alphaproteobacterial and gammaproteobacterial OTUs share low sequence similarity but are more closely affiliated with $16 \mathrm{~S}$ rRNA sequences received from other marine organisms, sediment, or the water column $[16,18,33,60-63,68,71]$. In addition, the aprA gene-based diversity analysis indicated the presence of one sulfate-reducing archaeal species and two Thiothrix spp.- and Thiobacillus plumbophilus-related potential SOB strains that might be general sponge-specific microorganisms; however, with respect to the limited sequence information available concerning sponge-SRP/SOB associations, their specificity might also be restricted to a certain group of sponges (e.g., genus or family) or possibly only to the species $P$. cf. corticata itself.

Overall, the bacterial community resident in $P$. cf. corticata was significantly distinct to those of the examined deep-water specimens of Sclerotiderma spp. [48], which were also collected from the Lesser Antilles area of the Caribbean Sea (coast of Curaçao and Bonnaire; 242-255 m depth). The phylotypes of Sclerotiderma spp. comprised representatives of the Alphaproteobacteria, Actinobacteria, Acidobacteria, Spirochaeta, and Chloroflexaceae, while members of the latter two groups were not present in $P$. cf. corticata. The identified OTUs of the three deep-water sponge species were only distantly related: The acidobacterial and actinobacterial phylotypes belonged to different sponge-specific clusters (SAB-Acido-I and SABActino-I in Sclerotiderma, SAB-Acido-III and SABActino-III in P. cf. corticata, see Fig. $3 \mathrm{c}$ and d), whereas the alphaproteobacterial OTUs represented unrelated bacteria classified as "generalist" and $P$. cf. corticata-"specialist" (PmCo-Alpha-I, see Fig. 3a). Nevertheless, as both studies were based on DGGE analysis of PCR products obtained with different primers, the nonoverlapping in their associated bacterial diversity might also be caused by primer-introduced different amplification bias $[58,66]$ and the sensitivity limitation of the DGGE method detecting only populations that comprise $1 \%$ or more of a sampled community [44]. The archaeal community of the Sclerotiderma spp. has not been assessed by Olson and McCarthy [48]. In P. cf. corticata, four crenarchaeotic phylotypes (SAA-Cren-I, PmCo-Cren-I) were detected that belonged to the cosmopolitan group C1a- $\alpha$ of MG-I [27, 38]; only two of them branched into the sponge-specific, monophyletic "sponge C group" [22, 32] (SAA-Cren-I, Fig. 3d). It is interesting to note that all sponge-derived $\mathrm{C} 1 \mathrm{a}-\alpha$ sequences were recently disputed to represent sponge-specific phylotypes because of the absence of significant host-clade specificity in clones of this group. Truly specific (potential mutualistic) associations between sponges and Archaea were postulated to exist only for Cenarchaeum symbiosum relatives (group $\mathrm{C} 1 \mathrm{a}$, Porifera $\mathrm{A}$ and $\mathrm{C}$ cluster) and axinellid sponges based on their parallel evolution (cospeciation) $[22,35]$. Besides the aforementioned $P$. cf. corticata-associated Crenarchaeota, a putative sponge- 
specific sulfate-reducing euryarchaeon was identified by the aprA gene analysis (Fig. 4). Euryarchaeal 16S rRNA clones have so far only been reported from Axechina raspailoides, Reniochalina stalagmites, Ptilocaulis sp. [22], and Rhopaloides odorabile (Methanomicrobiales relative) [69]. In contrast to our results, Holmes and Blanch reported the general absence of Archaea in Polymastia invaginata [22], which is a close relative of $P$. cf. corticata.

The 16S rRNA gene analysis with the universal primer sets demonstrated that the microbial consortium of $P$. cf. corticata and the ambient bacterioplankton were distinctly different, indicative for the low impact of the surrounding seawater on the sponge-microbe associations. In contrast, the usage of group-specific 16S rRNA, aprA, and amoA gene-targeting primers confirmed that seawater- and sediment-derived "generalist" phylotypes were present in $P$. cf. corticata (PmCo-Beta-I and PmCo-Beta-II; PmCo-ammonia-oxidizer$\mathrm{I}$ and PmCo-ammonia-oxidizer-II; PmCo-sulfur-oxidizer-I, PmCo-sulfur-oxidizer-II, and PmCo-sulfur-oxidizer-III). These phylotypes most likely corresponded to ammoniaoxidizing Nitrosospira relatives and putative sulfur (or sulfite)-oxidizing, yet uncultivated Alphaproteobacteria. The nondetection of the Nitrosospira relatives with the universal 16S rRNA gene-targeting primer pair might indicate that the abundance of the respective populations was below the detection limit of approximately $1 \%$ to $5 \%$ [44]. Vice versa, the failure to amplify the 16S rRNA genes of the spongespecific SAB-Beta-I members with the group-specific primer pair (CTO) [46] might indicate that these Betaproteobacteria were no chemolithoautrophic ammonia-oxidizers. Nevertheless, the CTO primer set [30] has been documented to bias the PCR-based analysis toward Nitrosospira relatives [36]. Because sponges are powerful filter-feeders (see [17, 19, 59, 67] and references therein) and are not able to discriminate between different types of food bacteria [70], even less abundant seawater- or sediment-derived microorganisms might be enriched by the stable and nutritionally rich microhabitat "sponge" ("microbial fermenter" [17]) and become part of the sponge-associated microbiota. As close relatives of the $P$. cf. corticata-associated Nitrosospira and Alphaproteobacteria were demonstrated to be abundant in the seawater-sediment interface [2, 10, 14, 41, 47], they might have represented transient bacterial populations that either served as "food bacteria" or resisted the phagocytosis process. In consequence, although a subset of the $P$. cf. corticata-associated microbial community (comprising especially the "sponge associates") will be transferred vertically as documented for several other sponges $[9,54,55]$, the ambient seawater had an influence on the composition of its associated microbial community (see presence of proven "generalists").

A correlation between the geographical location of sponges and the presence of major bacterial taxonomic groups in their associated microbiota was proposed by Hill et al. [18]. However, this postulated geographical impact appears to be of minor importance with respect to the results obtained from the Caribbean sponges ([18, 48] and this study). Acidobacteria, Deltaproteobacteria, and Nitrospira relatives that were proposed to be characteristic for warm-water sponges were also present in the $P$. cf. corticata specimen collected from $5^{\circ} \mathrm{C}$ cold deep-sea habitat. However, representatives of Bacteroidetes and Planctomycetes, which were suggested to be typical for microbial consortia of cold/temperate sponge, were absent. Indeed, several phylogenetic surveys demonstrated that the microbial consortia associated with different sponge species are highly diverse even if the hosts share one habitat [33, $51,60,62,63,68]$. In contradiction to the hypothesis of a uniform microbial signature of sponges across spatial and temporal scales $[15,16]$, the abundance, phylogenetic composition, and diversity of the host-associated microbial community mainly depends on the sponge-species and host state-depending interior factors as demonstrated by results of previous studies $[18,22,33,60-63,68]$ and confirmed by this work. The proportion of the "sponge associates," "specialists," and "generalists" populations appears to be a sponge-specific feature.

Spatial Differences in the Polymastia cf. corticata-associated Microbial Community

The 16S rRNA, aprA, and amoA gene-based phylogenetic investigation of the tissue sections, papillae, inner and outer cortex, and choanosome revealed that distinct bacterial and archaeal populations are associated with the different tissue regions of the deep-water specimen of $P$. cf. corticata. In accordance, spatial differences in the microbial community have recently been documented for the shallow-water sponge Tethya aurantium [63]. However, in contrast to the latter work, our study indicated that the local distribution of a phylotype in the host tissue depended on its phylogenetic affiliation (bacterial/archaeal division) and correlated with its classification as "sponge associate," "specialist," and "generalist," and its potential ecological role in the sponge. Indeed, compartmented sponges might provide distinct microenvironments as ecological niches for the different bacterial and archaeal populations. Nutrient-rich conditions within the mesohyl of $P$. cf. corticata (extensive phagocytosis by archaeocytes) might explain that the choanosomeand inner cortex-associated microbiota was the most complex. Notably, all identified Acidobacteria, Actinobacteria, and Deltaproteobacteria were (1) general sponge-specific members or at least specifically associated with $P$. cf. corticata and (2) restricted in their distribution to the choanosome. Sponge-associated Actinobacteria and Deltaproteobacteria (e.g., Entotheonella paulensis) have been reported to be prolific secondary metabolite producers 
$[34,42,52,53]$ and suggested to attribute largely to the chemical defense mechanisms of their host sponges against predators with biologically active compounds (repellents) and biofouling (see $[15,25]$ and references therein). Thus, their association with $P$. cf. corticata could have represented true mutualistic sponge-symbiont interactions. The functional role of the sponge-specific Acidobacteria is still unresolved because information concerning the physiology and metabolism of the marine acidobacterial members are not yet available and even limited for the abundant terrestrial species [26, 49]. In further support of a correlation between spatial distribution, sponge specificity, and the ecological role of the associated microorganisms, the aprA gene analysis demonstrated that the presumed general sponge-specific archaeal SRP and SOB strains (PmCo-sulfate-reducer-I, PmCo-sulfur-oxidizer-IV; Fig. 4) were also restricted to the host inner tissue regions. Consistently, potential sulfate-reducing strains (relatives of Desulfovibrionaceae and the Desulfarculus/Desulfomonile/ Syntrophus cluster) were only present in the choanosome sections of two shallow-water sponge species [20, 37]. As postulated for Geodia barretti [20], the associations of sponges with sulfate-reducing microorganisms might generally be synergistic. Most sponges alternate between periods of high water-pumping velocity and periods of low water circulation $[1,56]$; during the latter periods, oxygen becomes limited by the ongoing active respiration of sponge cells and aerobic microorganisms with the consequence of intermittent tissue anoxia. It was postulated that the anaerobic SRPs might benefit from the metabolic end products of sponge cells that switch to fermentation in these anoxic zones of the mesohyl; in turn, the microbial biomass might be consumed by the sponge cells ("bacterial farming") [20]. If oxygen is present again, the SRP-derived reduced sulfur compounds could be reoxidized by the activity of sulfur-oxidizing chemolithoautotrophs. Because potential members of both physiological groups were identified in the choanosome of $P$. cf. corticata by functional gene analysis, a sponge-specific, endosymbiotic sulfur cycle as described for marine oligochaetes $[3,8]$ may also be present in $P$. cf. corticata. As their closest related and cultivated species, Pelagibacter ubique (SAR11 clade) [12], the ubiquitous Alphaproteobacteria (cluster I to III; Fig. 4) might not rely on a sulfur-based chemolithoautotrophic lifestyle. As "generalists," they most likely represented opportunistic, transient bacterial populations obtained from the seawater and sediment.

In contrast to the aforementioned choanosome/inner cortex-associated bacteria, most microbes that were exclusively present in the outer tissue regions of $P$. cf. corticata were not general sponge-specific (exception SAB-GammaII representatives) but presented putative host-specific members of the Alphaproteobacteria, Gammaproteobacte- ria, and Crenarchaeota. These "specialists" might have been acquired by the settlement of free-living, opportunistic populations at the sponge surface with no benefit for the host. Indeed, the papillae- and outer cortex-associated microbial communities reflected the phylum level structure of the planktonic and surface sediment-associated microbiota at the Kahouanne Basin (Fig. 3).

The ubiquitous presence of potential ammonia- and nitrite-oxidizing bacteria and archaea in the entire sponge tissue probably reflected the overall availability of nitrogenous host waste products (e.g., ammonia, urea) in the sponge body. The coordinated metabolism of Nitrosospira and Cenarchaeum symbiosum/Nitrosopumilus maritimus relatives as ammonia-oxidizing bacteria/archaea [13, 28, 73] together with members of the genus Nitrospira as nitrite-oxidizing bacteria [29] (PmCo-Beta-I and PmCo-Beta-II and corresponding PmCo-ammonia-oxidizer-I and PmCoammonia-oxidizer-II; SAA-Cren-I and PmCo-Cren-I; SABNitrospira-I) might be responsible for the process of nitrification in $P$. cf. corticata as it has been proposed for other sponge species (see $[17,59]$ and references therein). In analogy to the mutualistic sponge-SRP/SOB interactions ("bacterial farming"), the chemolithoautotrophic $\mathrm{CO}_{2}$ fixation by the nitrifying microbial community could provide new carbohydrates for the host cells via microbe-sponge exchange. The members of the Nitrospira and inner cortex/ choanosome-associated SAA-Cren-I-Crenarchaeota belong to sponge-specific clusters, which might be indicative for long-term mutualistic interactions, whereas the $P$. cf. corticata-associated Nitrosospira relatives were most likely colonizers acquired by filtration processes from free-living populations that are generally abundant in marine habitats $[10,47]$.

Acknowledgements This study was supported by grants from the BMBF (project "Caribflux" under contract number 03G0154C), the DFG (under contract number KU 916/8-1), and the Max-PlanckSociety, Munich.

\section{References}

1. Bergquist PR (1978) Sponges. Hutchinson, London

2. Bernhard AE, Donn T, Giblin AE, Stahl DA (2005) Loss of diversity of ammonia-oxidizing bacteria correlates with increasing salinity in an estuary system. Environ Microbiol 7:1289-1297

3. Blazejak A, Erseus C, Amann R, Dubilier N (2005) Coexistence of bacterial sulfide oxidizers, sulfate reducers, and spirochetes in a gutless worm (Oligochaeta) from the Peru margin. Appl Environ Microbiol 71:1553-1561

4. Boury-Esnault N (2002) Family Polymastiidae Gray, 1867. In: Hooper NJA, van Soest RWM (eds) Systema Porifera: a guide to the classification of sponges. Kluwer, New York, NY, pp 201-219 
5. Brüser T, Lens PNL, Trüper HG (2000) The biological sulfur cycle. In: Lens PNL, Pol LH (eds) Environmental technologies to treat sulfur pollution. IWA Publishing, London, pp 47-86

6. Chombard C, Boury-Esnault N, Tillier S (1998) Reassessment of homology of morphological characters in tetractinellid sponges based on molecular data. Syst Biol 47:351-366

7. DeLong E (1992) Archaea in coastal marine environments. Proc Natl Acad Sci USA 89:5685-5689

8. Dubilier N, Mulders C, Ferdelman T et al (2001) Endosymbiotic sulphate-reducing and sulphide-oxidizing bacteria in an oligochaete worm. Nature 411:298-302

9. Enticknap JJ, Kelly M, Peraud O, Hill RT (2006) Characterization of a culturable alphaproteobacterial symbiont common to many sponges and evidence for vertical transmission via sponge larvae. Appl Environ Microbiol 72:3724-3732

10. Freitag TE, Prosser JI (2004) Differences between betaproteobacterial ammonia-oxidizing communities in marine sediments and those in overlying water. Appl Environ Microbiol 70: 3789-3793

11. Friedrich CG (1998) Physiology and genetics of sulfur-oxidizing bacteria. Adv Microb Physiol 39:235-289

12. Giovannoni SJ, Tripp HJ, Givan S et al (2005) Genome streamlining in a cosmopolitan oceanic bacterium. Science 309:1242-1245

13. Hallam SJ, Konstantinidis KT, Putnam N et al (2006) Genomic analysis of the uncultivated marine crenarchaeote Cenarchaeum symbiosum. Proc Natl Acad Sci USA 103:18296-18301

14. Hayashi T, Tanahashi M, Naganuma T (2007) Molecular diversity of the genes encoding ammonia monooxygenase and particulate methane monooxygenase from deep-sea sediments. Res Microbiol 2:530-537

15. Hentschel U, Fieseler L, Wehrl M et al (2003) Microbial diversity of marine sponges. In: Müller WEG (ed) Marine molecular biotechnology. Springer, Berlin, pp 59-88

16. Hentschel U, Hopke J, Horn M et al (2002) Molecular evidence for a uniform microbial community in sponges from different oceans. Appl Environ Microbiol 68:4431-4440

17. Hentschel U, Usher KM, Taylor MW (2006) Marine sponges as microbial fermenters. FEMS Microbiol Ecol 55:167-177

18. Hill M, Hill A, Lopez N, Harriott O (2006) Sponge-specific bacterial symbionts in the Caribbean sponge, Chondrilla nucula (Demospongiae, Chondrosida). Mar Biol 148:1221-1230

19. Hill RT (2004) Microbes from marine sponges: a treasure of biodiversity for natural products discovery. In: Bull AT (ed) Microbial diversity and bioprospecting. ASM, Washington, DC, pp 177-190

20. Hoffmann F, Larsen O, Thiel V et al (2005) An anaerobic world in sponges. Geomicrobiol J 22:1-10

21. Holmes AJ, Tujula NA, Holley M et al (2001) Phylogenetic structure of unusual aquatic microbial formations in Nullarbor caves, Australia. Environ Microbiol 3:256-264

22. Holmes B, Blanch H (2007) Genus-specific associations of marine sponges with group I crenarchaeotes. Mar Biol 150:759-772

23. Hooper NJA, van Soest RWM (2002) Systema Porifera: a guide to the classification of sponges. Kluwer, New York, NY

24. Huber H, Huber R, Stetter KO (2002) Thermoproteales. In: Dworkin M, Falkow E, Rosenberg E, Schleifer K-H, Stackebrandt E (eds) The prokaryotes. An evolving electronic resource for the microbial community. Fischer, New York, NY

25. Imhoff JF, Stöhr R (2003) Sponge-associated bacteria: general overview and special aspects of bacteria associated with Halichondria panicea. In: Müller WEG (ed) Marine molecular biotechnology. Springer, Berlin, pp 35-56

26. Janssen PH (2006) Identifying the dominant soil bacterial taxa in libraries of 16S rRNA and 16S rRNA genes. Appl Environ Microbiol 72:1719-1728

27. Karner MB, DeLong EF, Karl DM (2001) Archaeal dominance in the mesopelagic zone of the Pacific Ocean. Nature 409:507-510
28. Koennecke M, Bernhard AE, de la Torre JR et al (2005) Isolation of an autotrophic ammonia-oxidizing marine archaeon. Nature 437:543-546

29. Koops H-P, Pommerening-Röser A (2001) Distribution and ecophysiology of the nitrifying bacteria emphasizing cultured species. FEMS Microbiol Ecol 37:1-9

30. Kowalchuk GA, Stephen JR, De Boer W et al (1997) Analysis of ammonia-oxidizing bacteria of the beta subdivision of the class Proteobacteria in coastal sand dunes by denaturing gradient gel electrophoresis and sequencing of PCR-amplified 16S ribosomal DNA fragments. Appl Environ Microbiol 63:1489-1497

31. Lam P, Cowen JP, Jones RD (2004) Autotrophic ammonia oxidation in a deep-sea hydrothermal plume. FEMS Microbiol Ecol 47:191-206

32. Lee EY, Lee HK, Lee YK, Sim CJ, Lee JH (2003) Diversity of symbiotic archaeal communities in marine sponges from Korea. Biomolecular Engineering 20:299-304

33. Li Z, Hu Y, Liu Y et al (2007) 16S rDNA clone library-based bacterial phylogenetic diversity associated with three South China Sea sponges. World J Microbiol Biotechnol 23:1265-1272

34. Li Z-Y, Liu Y (2006) Marine sponge Craniella australiensisassociated bacterial diversity revelation based on $16 \mathrm{~S}$ rDNA library and biologically active Actinomycetes screening, phylogenetic analysis. Lett Appl Microbiol 43:410-416

35. Magot H, Acebal C, Toril E, Amils R, Fernandez PJL (2002) Consistent associations of crenarchaeal Archaea with sponges of the genus Axinella. Mar Biol 140:739-745

36. Mahmood S, Freitag TE, Prosser JI (2006) Comparison of PCR primer-based strategies for characterization of ammonia oxidizer communities in environmental samples. FEMS Microbiol Ecol $56: 482-493$

37. Manz W, Arp G, Schumann-Kindel G, Szewzyk U, Reitner J (2000) Widefield deconvolution epifluorescence microscopy combined with fluorescence in situ hybridization reveals the spatial arrangement of bacteria in sponge tissue. J Microbiol Methods 40:125-134

38. Massana R, Murray A, Preston C, DeLong E (1997) Vertical distribution and phylogenetic characterization of marine planktonic Archaea in the Santa Barbara Channel. Appl Environ Microbiol 63:50-56

39. Meyer B, Kuever J (2007) Molecular analysis of the distribution and phylogeny of dissimilatory adenosine-5'-phosphosulfate reductase-encoding genes (aprBA) among sulfur-oxidizing prokaryotes. Microbiology 153:3478-3498

40. Meyer B, Kuever J (2007) Phylogeny of the alpha and beta subunits of the dissimilatory adenosine-5'-phosphosulfate (APS) reductase from sulfate-reducing prokaryotes - origin and evolution of the dissimilatory sulfate-reduction pathway. Microbiology 153:2026-2044

41. Meyer B, Kuever J (2007) Molecular analysis of the diversity of sulfate-reducing and sulfur-oxidizing prokaryotes in the environment using aprA as functional marker gene. Appl Environ Microbiol 73:7664-7679

42. Montalvo NF, Mohamed NM, Enticknap JJ, Hill RT (2005) Novel actinobacteria from marine sponges. Antonie van Leeuwenhoek 87:29-36

43. Morrow C, Boury-Esnault N (2000) Redescription of the type species of the genus Polymastia Bowerbank, 1864 (Porifera, Demospongiae, Hadromerida). Zoosystema 22:327-335

44. Muyzer G, de Waal EC, Uitterlinden AG (1993) Profiling of complex microbial populations by denaturing gradient gel electrophoresis analysis of polymerase chain reaction-amplified genes coding for 16S rRNA. Appl Environ Microbiol 59:695700

45. Muyzer G, Teske A, Wirsen CO, Jannasch HW (1995) Phylogenetic relationships of Thiomicrospira species and their identification in deep-sea hydrothermal vent samples by denaturing 
gradient gel electrophoresis of $16 \mathrm{~S}$ rDNA fragments. Arch Microbiol 164:165-172

46. Nicolaisen MH, Ramsing NB (2002) Denaturing gradient gel electrophoresis (DGGE) approaches to study the diversity of ammonia-oxidizing bacteria. J Microbiol Methods 50:189-203

47. O'Mullan GD, Ward BB (2005) Relationship of temporal and spatial variabilities of ammonia-oxidizing bacteria to nitrification rates in Monterey Bay, California. Appl Environ Microbiol 71:697-705

48. Olson JB, McCarthy PJ (2005) Associated bacterial communities of two deep-water sponges. Aquat Microb Ecol 39:47-55

49. Quaiser A, Ochsenreiter T, Lanz C et al (2003) Acidobacteria form a coherent but highly diverse group within the bacterial domain: evidence from environmental genomics. Mol Microbiol 50:563-575

50. Rabus R, Hansen TA, Widdel F (1999) Dissimilatory sulfate- and sulfur-reducing prokaryotes. In: Dworkin M, Schleifer K-H, Stackebrandt E (eds) The prokaryotes: an evolving electronic database for the microbiological community. Springer, New York, NY, pp 1-87

51. Ridley CP, Faulkner DJ, Haygood MG (2005) Investigation of Oscillatoria spongeliae-dominated bacterial communities in four dictyoceratid sponges. Appl Environ Microbiol 71:7366-7375

52. Schirmer A, Gadkari R, Reeves CD et al (2005) Metagenomic analysis reveals diverse polyketide synthase gene clusters in microorganisms associated with the marine sponge Discodermia dissoluta. Appl Environ Microbiol 71:4840-4849

53. Schmidt EW, Obraztsova AY, Davidson SK, Faulkner DJ, Haygood MG (2000) Identification of the antifungal peptidecontaining symbiont of the marine sponge Theonella swinhoei as a novel deltaproteobacterium, "Candidatus Entotheonella palauensis". Mar Biol 136:969-977

54. Schmitt S, Weisz JB, Lindquist N, Hentschel U (2007) Vertical transmission of a phylogenetically complex microbial consortium in the vivparous sponge Ircinia felix. Appl Environ Microbiol 73:2067-2078

55. Sharp KH, Eam B, Faulkner DJ, Haygood MG (2007) Vertical transmission of diverse microbes in the tropical sponge Corticium sp. Appl Environ Microbiol 73:622-629

56. Simpson TL (1984) The cell biology of sponges. Springer, New York, NY

57. Suzuki F, Inagaki K, Takai K, Nealson KH, Horikoshi K (2004) Microbial diversity in inactive chimney structures from deep-sea hydrothermal systems. Microb Ecol 47:186-196

58. Suzuki MT, Giovannoni SJ (1996) Bias caused by template annealing in the amplification of mixtures of 16S rRNA genes by PCR. Appl Environ Microbiol 62:625-630

59. Taylor MW, Radax R, Steger D, Wagner M (2007) Spongeassociated microorganisms: evolution, ecology, and biotechnological potential. Microbiol Mol Biol Rev 71:295-347
60. Taylor MW, Schupp PJ, Dahllof I, Kjelleberg S, Steinberg PD (2004) Host specificity in marine sponge-associated bacteria, and potential implications for marine microbial ecology. Environ Microbiol 6:121-130

61. Taylor MW, Schupp PJ, de Nys R, Kjelleberg S, Steinberg PD (2005) Biogeography of bacteria associated with the marine sponge Cymbastela concentrica. Environ Microbiol 7:419-433

62. Thiel V, Leininger S, Schmaljohann R, Brümmer F, Imhoff JF (2007) Sponge-specific bacterial associations of the Mediterranean sponge Chondrilla nucula (Demospongiae, Tetractinomorpha). Microb Ecol 54:101-111

63. Thiel V, Neulinger SC, Staufenberger T, Schmaljohann R, Imhoff JF (2007) Spatial distribution of sponge-associated bacteria in the Mediterranean sponge Tethya aurantium. FEMS Microbiol Ecol 59:47-63

64. Vacelet J, Donadey C (1977) Electron microscope study of the association between some sponges and bacteria. J Exp Mar Biol Ecol 30:301-314

65. Vetriani C, Jannasch HW, MacGregor BJ, Stahl DA, Reysenbach A-L (1999) Population structure and phylogenetic characterization of marine benthic archaea in deep-sea sediments. Appl Environ Microbiol 65:4375-4384

66. von Wintzingerode F, Gobel UB, Stackebrandt E (1997) Determination of microbial diversity in environmental samples: pitfalls of PCR-based rRNA analysis. FEMS Microbiol Rev 21:213-229

67. Wang G (2006) Diversity and biotechnological potential of the sponge-associated microbial consortia. J Ind Microbiol Biotech $33: 545-551$

68. Webster NS, Negri AP, Munro M, Battershill CN (2004) Diverse microbial communities inhabit Antarctic sponges. Environ Microbiol 6:288-300

69. Webster NS, Watts JEM, Hill RT (2001) Detection and phylogenetic analysis of novel crenarchaeote and euryarchaeote $16 \mathrm{~S}$ ribosomal gene sequences from a Great Barrier Reef sponge. Mar Biotechnol 3:600-608

70. Wehrl M, Steinert M, Hentschel U (2007) Bacterial uptake by the marine sponge Aplysina aerophoba. Microb Ecol 53:355-366

71. Wichels A, Wurtz S, Dopke H, Schutt C, Gerdts G (2006) Bacterial diversity in the breadcrumb sponge Halichondria panicea (Pallas). FEMS Microbiol Ecol 56:102-118

72. Wilkinson CR (1978) Microbial associations in sponges. III. Ultrastructure of the in situ association in coral reef sponges. Mar Biol 49:177-185

73. Wuchter C, Abbas B, Coolen MJL et al (2006) Archaeal nitrification in the ocean. Proc Natl Acad Sci USA 103:1231712322

74. Zhou JZ, Bruns MA, Tiedje JM (1996) DNA recovery from soils of diverse composition. Appl Environ Microbiol 62:316-322 